and preliminarily validated a self-administered screening questionnaire, called DETection of Arthritis in Inflammatory boweL diseases (DETAIL) ${ }^{1}$

Objectives: To validate the DETAIL questionnaire in a multicenter cohort of IBD patients enrolled at ten Gastroenterology and Rheumatology Units in Italy. Methods: The DETAIL instrument is a 6-item questionnaire developed through a Delphi method ${ }^{1}$. From October 2018 to March 2019, consecutive adult patients with IBD, Crohn's disease (CD) or ulcerative colitis (UC), filled out independently the DETAIL in the outpatient waiting room. Thereafter, within 2 weeks a blinded rheumatologist assessed all the patients, irrespectively of the DETAIL results, and classified them to be affected or not by SpA according to ASAS criteria. The performance of the DETAIL was evaluated trough Bayesian analysis, defining for each item of the questionnaire the sensitivity, specificity, positive (LR+) and negative (LR-) likelihood ratios.

Results: Overall, 418 IBD patients filled out the DETAIL questionnaire. Upon rheumatological evaluation, $102(24.4 \%)$ patients received a diagnosis of SpA. Of the six questions, the best performances were found in item $6(L R+3.77)$, reporting inflammatory back pain at night, and in item $3(L R+3.31)$, exploring Achilles enthesitis. The presence of back pain lasting more than three months $(L R+2.91)$, of back pain with inflammatory features $(L R+2.55)$ and a history of dactylitis $(L R+2.55)$, showed also a fairly good performance, whereas a history of peripheral synovitis was slightly worse $(L R+2.16)$. The combination of at least three items answered affirmatively yielded a post-test probability of SpA of $75 \%$ or more. The presence of alternative diagnoses, such as osteoarthritis and fibromyalgia, represented a minor confounder.

Conclusion: The DETAIL questionnaire is the first screening tool for the early detection of SpA/IBD that has been validated by a multicenter study group. References:

[1] Di Carlo M, Luchetti MM, Benfaremo D, Di Donato E, Mosca P, Maltoni S, Benedetti A, Gabrielli A, Grassi W, Salaffi F. The DETection of Arthritis in Inflammatory boweL diseases (DETAIL) questionnaire: development and preliminary testing of a new tool to screen patients with inflammatory bowel disease for the presence of spondyloarthritis. Clin Rheumatol. 2018 Apr;37(4):1037-1044.

Acknowledgments: We are grateful to all the members of the GRADES-IBD study group for their outstanding help in the enrollment of patients.

We also would like to acknowledge the "Società Italiana di Gastro-Reumatologia" (SIGR) for its help and assistance in the constitution of the multidisciplinary network.

Disclosure of Interests: None declared

DOI: 10.1136/annrheumdis-2020-eular.3726

\section{FRI0321 UTILITY OF THE ASAS HEALTH INDEX \\ QUESTIONNAIRE AS A TOOL FOR HEALTH ASSESSMENT IN PATIENTS WITH SPONDYLOARTHRITIS AND ITS ASSOCIATION WITH DISEASE ACTIVITY, FUNCTIONALITY, MOBILITY, AND STRUCTURAL DAMAGE}

M. Á. Puche Larrubia ${ }^{1}$, C. López-Medina ${ }^{1,2}$, M. D. C. Castro Villegas ${ }^{1}$, R. Ortega Castro $^{1}$, M. Ladehesa Pineda ${ }^{1}$, P. S. Laura ${ }^{1}$, G. G. Ignacio ${ }^{1}$, J. M. SequíSabater $^{1}$, M. D. C. Abalos-Aguilera ${ }^{1}$, I. C. Aranda-Valera ${ }^{1}$, G. C. Juan Luis ${ }^{1}$, A. Escudero Contreras ${ }^{1}$, E. Collantes-Estevez ${ }^{1} .{ }^{1}$ Reina Sofia University Hospital, Rheumatology Service/IMIBIC/Cordoba University, Córdoba, Spain; ${ }^{2}$ Cochin Hospital, Rheumatology Service, Paris, France

Background: The ASAS Health Index (ASAS-HI) questionnaire, a tool that measures the impact of the disease on the health in patients with Spondyloarthritis ( $\mathrm{SpA})$, has been recently validated. However, there are still no studies evaluating the utility of this questionnaire in daily clinical practice.

Objectives: The objective of this study is to evaluate the association of ASAS-HI with disease activity, functionality, mobility, and structural damage in patients with SpA.

Methods: This is an observational, cross-sectional and single-center study in which 126 consecutive patients with SpA were included. Sociodemographic data, scores related to disease activity (BASDAI and ASDAS), functionality (BASFI), structural damage (cervical, lumbar and total mSASSS), mobility (BASMI and UCOASMI), quality of life (ASAS-HI) and the presence of concomitant fibromyalgia (evaluated with the FIRST questionnaire) were obtained from all patients. The ASAS-HI questionnaire was considered as the main outcome (scale from 0 to 17). Pearson's correlation coefficient was used to evaluate the association of the different continuous variables with each other. Student's t-test was used to compare the ASAS-HI between different subgroups of patients (men vs. women, ASDAS $>2,1$ vs. ASDAS $\leq 2,1$ and fibromyalgia + vs. fibromyalgia-). Finally, a multivariate linear regression was performed to determine which factors explain the variability of ASAS-HI in these patients Results: Among the 126 patients included, 83 (65.9\%) were men, with a mean age of $45.1 \pm 12.3$ years and a mean disease duration of $18.7 \pm 14.5$ years. The mean ASAS-HI score in all patients was $4.7 \pm 4.0$, showing a "strong" positive linear correlation $(r>0.60)$ with BASDAI and BASFI, and "moderate" positive
( $r=0.40$ to 0.60 ) with Global VAS and ASDAS (Figure 1). Patients with fibromyalgia showed a significantly higher ASAS-HI score compared with patients without fibromyalgia $(9.5 \pm 3.2$ vs $3.7 \pm 3.4$, respectively). In addition, patients with high disease activity (ASDAS $>2,1$ ) showed a higher mean score in ASAS-H compared with those with low activity (ASDAS $\leq 2,1)(5.8 \pm 3.8$ vs $2.0 \pm 2.4$ $p<0,001)$.

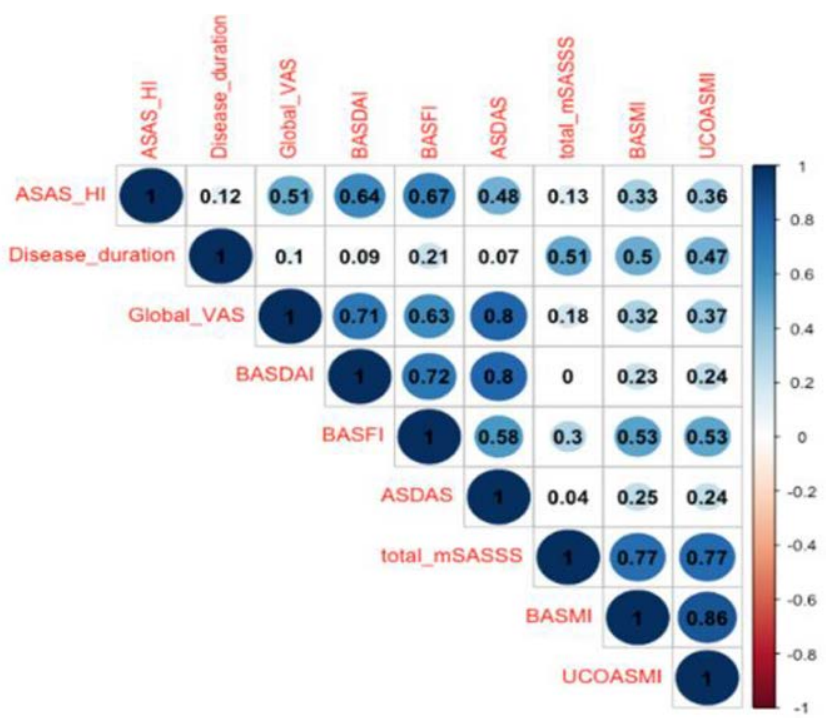

Figure 1. Simple linear correlation (Pearson's $r$ ) between the different variables studied.

Finally, multiple linear regression showed that $57,4 \%(R 2=0,574)$ of the ASAS-H variability is explained by the presence of concomitant fibromyalgia $(\beta=2.23$ $95 \% \mid \mathrm{IC} 0.73$ to $3.80, p=0.004)$, BASDAI ( $\beta=0.62,95 \% \mathrm{IC} 0.25$ to $0.97, p=0.001$ ) and BASFI ( $\beta=0.57,95 \% \mathrm{IC} 0.26$ to $0.88, p=0.001)$.

Conclusion: In our study, the impairment of the quality of life in patients with $\mathrm{SpA}$ was mainly associated with a high disease activity (BASDAI), worsening functionality (BASFI) and with the presence of concomitant fibromyalgia. Neithe mSASSS nor UCOASMI was associated with a change in ASAS-HI; thus, in ou patients neither structural damage nor mobility seem to influence the quality of life. In a patient with a high ASAS-HI we must evaluate the presence of concomitant fibromyalgia.

Acknowledgments: The authors wish to thank all patients who participated in the study.

Disclosure of Interests: María Ángeles Puche Larrubia: None declared, Clementina López-Medina: None declared, María del Carmen Castro Villegas: None declared, Rafaela Ortega Castro: None declared, MLourdes Ladehesa Pineda: None declared, Pérez Sánchez Laura: None declared, Gómez García Ignacio: None declared, José Miguel Sequí-Sabater: None declared, Maria del Carmen Abalos-Aguilera: None declared, Inmaculada Concepcion Aranda-Valera: None declared, Garrido Castro Juan Luis: None declared, Alejandro Escudero Contreras Grant/research support from: ROCHE and Pfizer, Speakers bureau: ROCHE, Lilly, Bristol and Celgene., Eduardo Collantes-Estevez: None declared DOI: 10.1136/annrheumdis-2020-eular.5640

\section{FRI0322 INSULIN RESISTANCE IN NON-DIABETES PATIENTS WITH SPONDYLOARTHRITIS}

J. C. Quevedo-Abeledo ${ }^{1}$, F. Genre ${ }^{2}$, J. Rueda-Gotor ${ }^{3}$, A. Corrales ${ }^{3}$,

V. Hernández-Hernández ${ }^{4}$, N. Fañanas-Rodríguez ${ }^{5}$, B. Lavín-Gómez ${ }^{5}$, D. F. Esmeralda ${ }^{4}$, A. De Vera-González ${ }^{6}, A$. Delgado-González ${ }^{6}$, L. De ArmasRillo $^{7}$, M. T. García-Unzueta ${ }^{5}$, M. A. González-Gay ${ }^{3}$, I. Ferraz-Amaro ${ }^{4}{ }^{1}$ Division of Rheumatology, Hospital Doctor Negrín, Las Palmas de Gran Canaria, Spain, Las Palmas de Gran Canaria, Spain; ${ }^{2}$ Epidemiology, Genetics and Atherosclerosis Research Group on Systemic Inflammatory Diseases, Hospital Universitario Marqués de Valdecilla, IDIVAL, Santander, Spain; ${ }^{3}$ Division of Rheumatology, Hospital Universitario Marqués de Valdecilla, Santander, Spain; ${ }^{4}$ Hospital Universitario de Canarias, Division of Rheumatology, Santa Cruz de Tenerife, Spain; ${ }^{5}$ Division of Endocrinology, Hospital Universitario Marqués de Valdecilla, Santander, Spain; ${ }^{6}$ Division of Central Laboratory, Hospital Universitario de Canarias, Tenerife, Spain, Santa Cruz de Tenerife, Spain: ${ }^{7}$ Universidad Europea de Canarias, Santa Cruz de Tenerife, Spain

Background: Insulin resistance (IR) is a state in which a given concentration of insulin is associated with a subnormal glucose response. IR constitutes a major underlying abnormality driving cardiovascular disease in the general population 
and has been linked to inflammatory diseases. In this sense, several reports have confirmed that inflammation worsens IR and impairs pancreatic $\beta$-cell function in inflammatory diseases such as rheumatoid arthritis and systemic lupus erythematosus.

Objectives: In this study we aimed to determine the prevalence of IR in patients with spondyloarthritis $(\mathrm{SpA})$ compared to controls, and whether IR can be explained by disease-related features in SpA patients.

Methods: Study of 577 subjects, 306 patients diagnosed with SpA according to ASAS criteria and 271 controls. Insulin and C-peptide serum levels, IR and $\beta$-cell function (\%B) indexes by homeostatic model assessment (HOMA2), and lipid profiles were assessed in patients and controls. A multivariate regression analysis was performed to evaluate the differences in IR indexes between patients and controls and to determine how IR is associated with disease-related characteristics.

Results: SpA patients showed higher serum levels of insulin (8.7 [4.8-15.9] vs. 8.0 [5.7-11.2] uU/ml, $\mathrm{p}=0.001)$ and $\mathrm{C}$ peptide (1.4 [0.7-2.5] vs. $1.2[0.7-1.7] \mathrm{ng} /$ $\mathrm{ml}, \mathrm{p}=0.000$ ) than controls in the univariate analysis. Similarly, HOMA2-B\% and IR were all significantly higher in SpA patients. These differences were still evident when the comparisons were made after the multivariate analysis had been adjusted for traditional IR-related factors (sex, age, BMI, hypertension, dyslipidemia, smoking and, cholesterol), glucocorticoids intake, insulin and C-peptide. Moreover, HOMA2-B\% and HOMA2-IR scores, both calculated with insulin or $\mathrm{C}$-peptide, yielded statistically higher significant values in $\mathrm{SpA}$ patients than controls.

Classic IR-related factors (age, BMI, waist circumference, hypertension, obesity, dyslipidemia, atherogenic index, and triglycerides), as well as CRP serum levels, were all related, to a greater or lesser degree, with IR and $\beta$-cell function. Regarding disease-related data, ASDAS-CRP, BASFI and BASMI scores were positively associated with IR; and BASMI and BASDAI scores were positively related to HOMA2-\%B-C peptide. Moreover, the use of NSAID and prednisone were, respectively, positive and negatively related to $\beta$-cell function. However, only some of the associations of the univariate analysis were maintained after adjusting for confounders. In this sense, disease duration (beta coefficient 2 $[95 \% \mathrm{Cl} 1-3], \mathrm{p}=0.001$ ) and positivity for HLA-B27 (beta coefficient $30[95 \% \mathrm{Cl}$ $12-49$ ], $p=0.002$ ) were associated with higher $\beta$-cell functionality after the multivariate analysis.

Conclusion: Patients with SpA have an increased IR compared to controls. SpA disease-related data like disease duration and HLA-B27 are independently associated with $\beta$-cell dysfunction.

Disclosure of Interests: Juan Carlos Quevedo-Abeledo Speakers bureau: Abbvie, Fernanda Genre: None declared, Javier Rueda-Gotor: None declared, Alfonso Corrales Speakers bureau: Abbvie, Vanessa Hernández-Hernández Speakers bureau: Pfizer, Abbvie, MSD, Natalia Fañanas-Rodríguez: None declared, Bernardo Lavín-Gómez: None declared, delgado frias esmeralda Speakers bureau: Pfizer, Abbvie, MSD, Antonia de Vera-González: None declared, Alejandra Delgado-González: None declared, Laura de Armas-Rillo: None declared, Maria Teresa García-Unzueta: None declared, Miguel A González-Gay Grant/research support from: Pfizer, Abbvie, MSD, Speakers bureau: Pfizer, Abbvie, MSD, Iván Ferraz-Amaro Grant/research support from: Pfizer, Abbvie, Speakers bureau: Pfizer, Abbvie, MSD.

DOI: 10.1136/annrheumdis-2020-eular.619

\begin{tabular}{|l|l|}
\hline FRI0323 & THE PRESENCE OF SPONDYLOARTHRITIS IS \\
& ASSOCIATED WITH HIGHER CLINICAL DISEASE \\
& ACTIVITY IN PATIENTS WITH EARLY CROHN'S \\
& DISEASE: RESULTS OF A PROSPECTIVE COHORT \\
& STUDY
\end{tabular}

V. Rios Rodriguez ${ }^{1,2}$, M. Protopopov ${ }^{1}$, F. Proft ${ }^{1}$, S. Lüders ${ }^{1}$, J. Rademacher ${ }^{1,2}$, H. Haibel ${ }^{1}$, M. Verba ${ }^{1}$, J. Sieper ${ }^{1}$, E. Sonnenberg ${ }^{1}$, M. Schumann ${ }^{1}$, L. I. Kredel ${ }^{1}$, B. Siegmund ${ }^{1}$, D. Poddubnyy ${ }^{1,3} .{ }^{1}$ Charité - Universitätsmedizin Berlin, Berlin, Germany; ${ }^{2}$ Berlin Institute of Health, Berlin, Germany; ${ }^{3}$ Deutsches RheumaForschungszentrum (DRFZ), Berlin, Germany

Background: Inflammatory bowel disease (IBD) and specifically Crohn's disease (CD) is known to be associated with spondyloarthritis (SpA). However, only little is known about factors associated with the development of spondyloarthritis in CD.

Objectives: To identify factors associated with the presence of $\mathrm{SpA}$ in a cohort of patients with $\mathrm{CD}$.

Methods: Patients with a definite diagnosis of $C D$ naïve to or not being treated with biological agents for at least 3 months were included in a CD-arm of the German Spondyloarthritis Inception Cohort (GESPIC-Crohn). Gastroenterologists were encouraged to include consecutively recently diagnosed $C D$ patients. Patients were classified according to the Montreal classification including location and behavior of CD. Patients received a structured assessment of
SpA manifestations (including magnetic resonance imaging of sacroiliac joints and spine) by a rheumatologist who was responsible for the final diagnosis of $\mathrm{SpA}$ / no SpA. Clinical activity of CD was assessed by the Harvey-Bradshaw Index ( $\mathrm{HBI}$ ). In addition, colonoscopy was performed, Simple endoscopic Score for Crohn's Disease (SES-CD) was determined and fecal calprotectin was measured.

Results: A total of 108 patients with $C D$ were enrolled. The mean (mean \pm SD) age was $36.6 \pm 12.7$ years, and $C D$ symptom duration was $5.3 \pm 7.4$ years. At baseline, $44(40.7 \%)$ patients were treated with non-biologic immunomodulating drugs: $16(14.8 \%)$ patients received mesalazine, $27(25.0 \%)$ azathioprine, and $1(0.9 \%)$ methotrexate. Oral steroids were given to $38(35.2 \%)$ patients. A total of $103(96.3 \%)$ patients were biologics naïve. SpA was diagnosed in $23(21.3 \%)$ patients: 12 had axial SpA and 11 peripheral SpA. Patients with SpA had higher prevalence of HLA-B27, of clinical SpA features (back pain, inflammatory back pain, peripheral arthritis, enthesitis), higher level of CRP and higher activity of $\mathrm{CD}$ as measured by the HBI. There were not substantial differences between $\mathrm{SpA}$ vs. non-SpA patients in terms of CD duration, endoscopic activity, disease location or behavior, or treatment, except for mesalazine, which was more frequently administered in patients with $\mathrm{SpA}$ than non-SpA $(39.1 \%$ vs. $8.2 \%$, $\mathrm{p}=0.001$, respectively).

Conclusion: $\mathrm{SpA}$ was present in $21 \%$ of patients with $\mathrm{CD}$ in this early cohort with almost equal proportions of axial and peripheral forms. Presence of HLAB27 and higher clinical activity of CD were associated with the presence of SpA.

TABLE. Baseline demographic and clinical characteristics of the included patients with Crohn's disease with or without spondyloarthritis.

\begin{tabular}{|c|c|c|c|c|}
\hline VARIABLE & $\begin{array}{l}\text { TOTAL } \\
n=108\end{array}$ & $\begin{array}{l}\mathrm{SpA} \\
\mathrm{n}=23\end{array}$ & $\begin{array}{c}\text { No } S p A \\
n=85\end{array}$ & $\mathrm{P}$ \\
\hline Age, years, mean $\pm S D$ & $36.6 \pm 12.7$ & $37.5 \pm 11.3$ & $36.3 \pm 13.1$ & 0.44 \\
\hline Male sex, $\mathrm{n}(\%)$ & $50(46.3)$ & $10(43.5)$ & $40(47.1)$ & 0.82 \\
\hline $\mathrm{CD}$ symptom duration, years, mean $\pm \mathrm{SD}$ & $5.3 \pm 7.4$ & $5.4 \pm 7.2$ & $5.1 \pm 7.5$ & 0.63 \\
\hline HLA-B27 positive, n (\%) & $13(12.0)$ & $6(26.1)$ & $7(8.2)$ & 0.03 \\
\hline \multicolumn{5}{|l|}{ Montreal classification } \\
\hline Location: L1 - ileal & $68(63.0)$ & $13(56.5)$ & $55(64.7)$ & 0.48 \\
\hline L2 - colonic & 0 & 0 & 0 & \\
\hline L3 - ileocolonic & $39(36.1)$ & $7(30.4)$ & $32(37.6)$ & 0.63 \\
\hline L4 - isolated upper disease & $10(9.3)$ & $3(13.0)$ & $7(8.2)$ & 0.44 \\
\hline Behavior: & 69 (63.9) & $15(65.2)$ & 54 (63.5) & 1.00 \\
\hline \multicolumn{5}{|l|}{ B1 - non-stricturing, non-penetrating } \\
\hline B2 - stricturing & $19(17.6)$ & $4(17.4)$ & $15(17.6)$ & 1.00 \\
\hline B3 - penetrating & $6(5.6)$ & 0 & $6(7.1)$ & 0.34 \\
\hline Peri-anal disease & $7(6.5)$ & $2(8.7)$ & $5(5.9)$ & 0.64 \\
\hline C-reactive protein, $\mathrm{mg} / \mathrm{l}$, mean $\pm \mathrm{SD}$ & $10.7 \pm 24.8$ & $13.6 \pm 23.2$ & $10.0 \pm 25.3$ & 0.02 \\
\hline Harvey-Bradshaw Index, mean $\pm S D$ & $3.6 \pm 4.0$ & $5.5 \pm 4.7$ & $3.1 \pm 3.6$ & 0.01 \\
\hline Fecal calprotectin, mcg/d, mean \pm SD & $185.9 \pm 213.7$ & $211.7 \pm 243.8$ & $179.5 \pm 207.9$ & 0.43 \\
\hline \multicolumn{5}{|l|}{ Treatment of $C D$} \\
\hline Mesalazine, n (\%) & $16(14.8)$ & $9(39.1)$ & $7(8.2)$ & 0.001 \\
\hline Methotrexate, n (\%) & $27(25.0)$ & $3(13.0)$ & $24(28.2)$ & 0.18 \\
\hline Azathioprine, $\mathrm{n}(\%)$ & $1(0.9)$ & 0 & $1(1.2)$ & 1.00 \\
\hline Biologics naive, $\mathrm{n}(\%)$ & $103(96.3)$ & $22(95.7)$ & 81 (96.4) & 1.00 \\
\hline
\end{tabular}

Figure. Spondyloarthritis manifestations in patients with Crohn's disease.

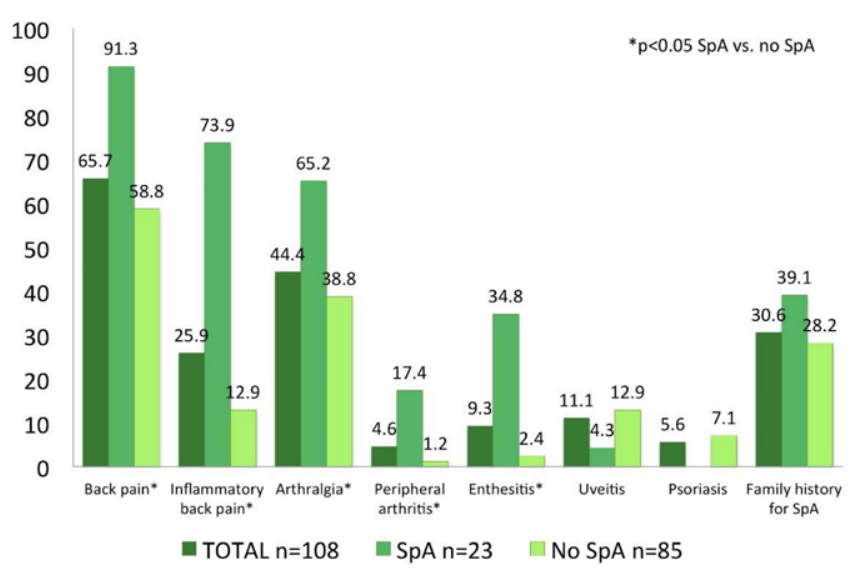

Disclosure of Interests: Valeria Rios Rodriguez Consultant of: Abbvie Novartis, Mikhail Protopopov Consultant of: Novartis, Fabian Proft Grant/ research support from: Novartis Pharma $\mathrm{GmbH}$, Consultant of: Consultancy / speaker fees from: Abbvie, BMS, Celgene, Lilly, MSD, Novartis, Pfizer, Roche, 